\title{
Adenocarcinoma of the duodenum with a duodeno-colic fistula occurring after childhood Wilms' cancer
}

\author{
Ian L.P. Beales and Humphrey J. Scott ${ }^{1}$ \\ Department of Gastroenterology and ${ }^{1}$ Department of Surgery, Hammersmith Hospital, Du Cane Road, \\ London W12 0NN, UK
}

\begin{abstract}
Summary: A case of a 44 year old man with a duodeno-colic fistula secondary to an adenocarcinoma of the second part of the duodenum is described. An asymptomatic leiomyoma of the second part of the duodenum was also present. The patient had been treated successfully for a right Wilms' cancer in childhood with surgery and radiotherapy. There are no previous reports of a duodenal carcinoma arising following a Wilms' tumour and cases of gastrointestinal adenocarcinoma arising as second malignancies following Wilms' tumours are reviewed. The aetiology of duodeno-colic fistulas is reviewed. Duodenal carcinoma is a unusual cause of duodeno-colic fistulas and this case may be unique in that respect.
\end{abstract}

\section{Introduction}

Wilms' tumour of the kidney is a relatively common childhood cancer and increasing numbers of patients are achieving survival into mature adult life. There is an increased risk of second cancers in these survivors. This report describes the occurrence of a duodenal carcinoma following successful treatment of a Wilms' tumour by surgery and radiotherapy, and reviews the previous literature of gastrointestinal cancer following a Wilms' tumour. Duodenal cancer is a rare tumour and there was no evidence of any of the previously recognized associations. Gastrointestinal cancer may be a long-term complication of the successful treatment to this primary cancer.

Fistulas connecting the duodenum and colon are uncommon in clinical practice, although those due to malignancy are usually due to colonic carcinomas, there seem to be no previous reports of a duodenal cancer leading to a duodeno-colic fistula.

\section{Case report}

A 44 year old man presented with a 3 month history of watery diarrhoea associated with a weight loss of $20 \mathrm{~kg}$. At the age of five he had been treated for a right Wilms' tumour (nephroblastoma), and had undergone right nephrectomy and abdominal radiotherapy. To the time of his subsequent presentation progress had been unremarkable. The full family history was non-contributory.

Correspondence: H.J. Scott, M.S., F.R.C.S., 4 Hambledon Road, London SW18 5UB.

Accepted: 29 March 1994
Examination only revealed tender hepatomegaly. Colonoscopy identified a protruding mass on the medial wall of the mid ascending colon and, on upper gastrointestinal endoscopy, a tight ulcerating, circumferential stricture was found in the second part of the duodenum. There was food residue in the stomach suggesting outflow obstruction. Computerized tomography (CT) showed a large periduodenal mass and multiple hepatic metastases (Figure 1). A duodeno-colonic fistula was confirmed by barium meal (Figure 2). Histology from the duodenum confirmed a poorly differentiated adenocarcinoma and colonic biopsies showed normal epithelium covering deep invasion of the mucosa and submucosa by tumour with the same features.

He underwent palliative gastrojejunostomy and iliotransverse anastomoses in order to bypass the stricture and fistula. He recovered from surgery and passed solid stool, but his condition continued to deteriorate and he developed obstructive jaundice. The patient died 56 days after presentation.

A postmortem examination found evidence of a large poorly differentiated adenocarcinoma mass arising proximal to the ampulla of Vater, involving and encasing the second part of the duodenum. There was extension to the ascending colon and caecum with involvement of mesenteric and the porta hepatis lymph nodes. There was occlusion of the communication between segmental bile ducts by primary tumour and involved lymph nodes. There was no sign of diffuse gastrointestinal polyposis or other mucosal or skeletal abnormalities. An unsuspected finding was a leiomyoma in the duodenal bulb. 


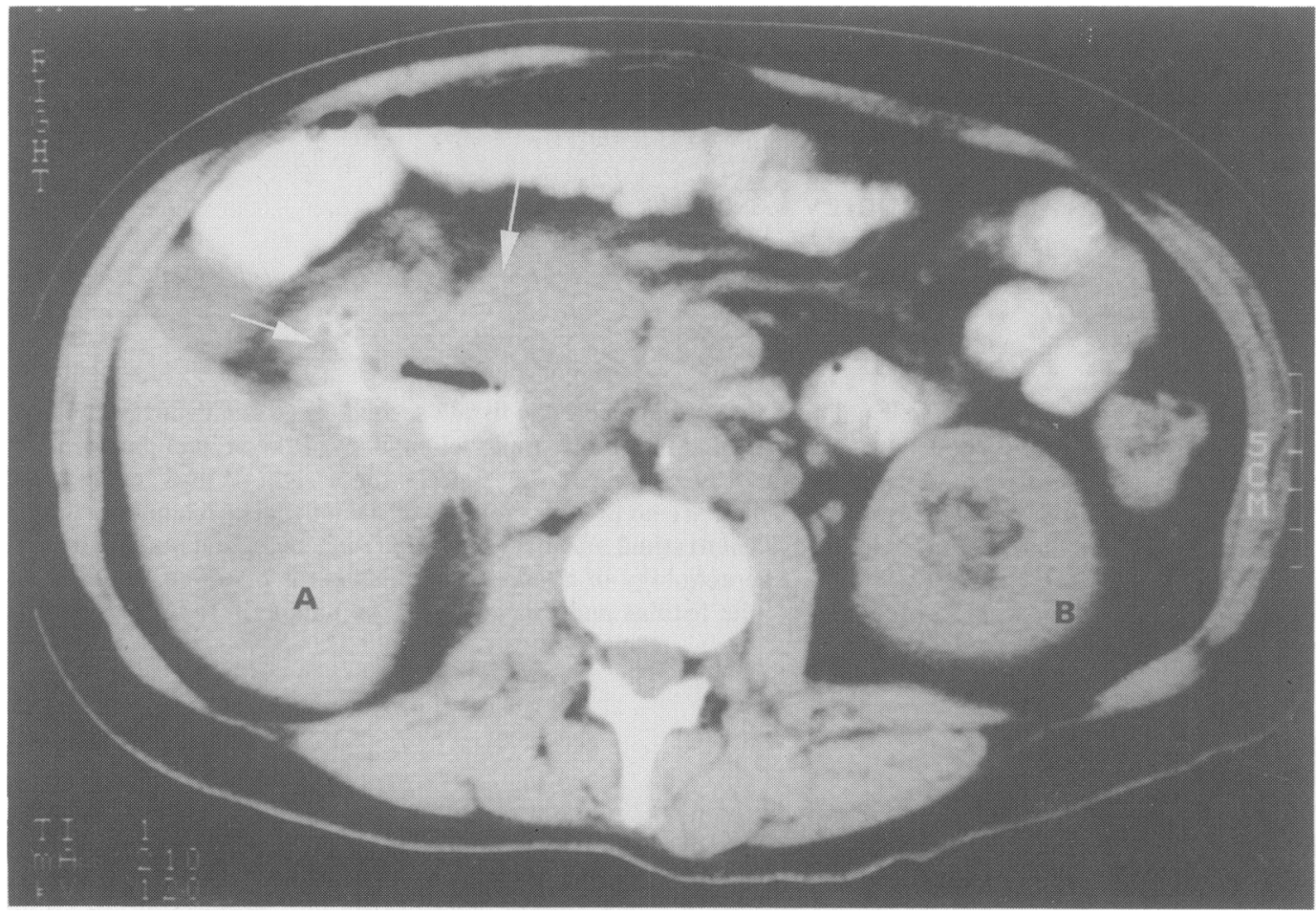

Figure 1 CT scan through the abdomen illustrating the large peri-duodenal soft tissue mass (arrows), multiplk intrahepatic metastases (A) and the single hypertrophied left kidney (B). Gastrograffin contrast can be seen in the duodenal lumen within the soft tissue tumour mass.

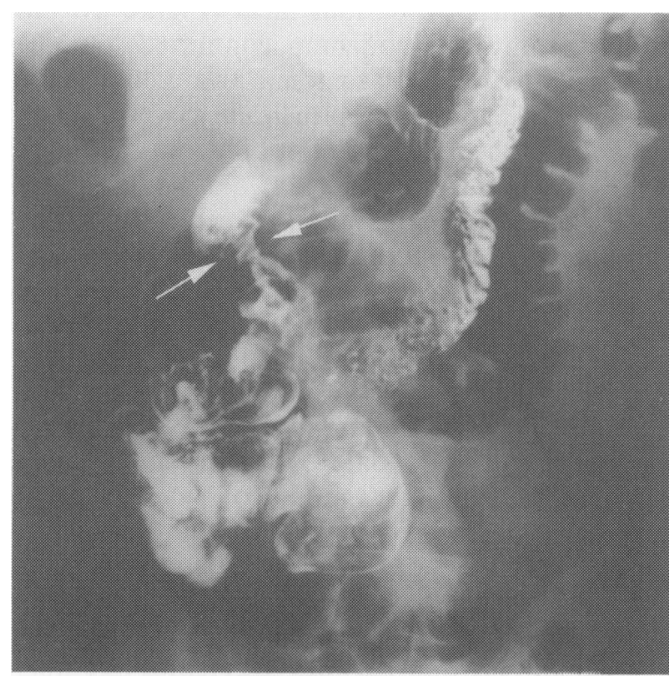

Figure 2 Barium meal examination with rectal air nsufflation showing irregular stricturing of the proximal second part of the duodenum (arrows), and abnormal jassage of contrast directly into the right colon and saecum.

\section{Discussion}

Second cancers after successful therapy for Wilms' tumour have been recognized to be a problem. At 20 years an incidence of $4 \%$ has been reported ${ }^{1}$ and the incidence continues to rise thereafter (the mean risk of second malignancies for all childhood cancers combined is about $3 \%$ at 20 years). ${ }^{2}$ Although no specific second tumour type has been definitely implicated, the risk of hepatocellular carcinoma after right Wilms' tumours and radiotherapy may be increased. ${ }^{3}$ There are four previous cases of bowel adenocarcinoma arising following childhood Wilms' cancer; one carcinoma of the rectum ${ }^{4}$ and three colonic cancers. ${ }^{2,5,6}$ All of these patients received abdominal radiotherapy but not all chemotherapy. Certainly in two of these, (1) hepatic flexure adenocarcinoma following right Wilms' and radiotherapy ${ }^{5}$ and (2) splenic flexure poorly differentiated adenocarcinoma following left Wilms' tumour, radiotherapy and chemotherapy, ${ }^{6}$ the second cancer seemed to lie directly within the radiotherapy field (as in the present case).

Duodenal cancer is rare, especially that not 
arising from the ampulla, and has previously been associated with coeliac disease, ${ }^{7}$ Crohn's disease both with and without dysplasia, ${ }^{8}$ familial polyposis syndromes ${ }^{9}$ and non-polyposis family cancer syndromes. ${ }^{10}$ There was no evidence of any of these factors in this patient. Full family data are not available on the four cases reported previously. The Wilms' tumour propensity gene (WT1) has now been identified and cloned, but there is no evidence at present of involvement of this tumour repressor gene in either controlling normal gastrointestinal tract proliferation or carcinogenesis. ${ }^{11,12}$ This gene is located at the $11 \mathrm{p} 13$ locus and loss of alleles at this site has been described in both Wilms' and hepatocellular cancers, although not as yet in those arising sequentially. ${ }^{13}$ Other genetic loci are also likely to be involved in Wilms' cancer and, although their exact nature and function are not as yet clear, it is possible that these may be involved in the increased risk of second tumours. ${ }^{11}$

Breslow et al. ${ }^{1}$ reported that the incidence of all second cancers in survivors may be increased up to 12-fold by the adjuvant use of radiotherapy over and above the excess risk associated with Wilms' tumour alone.

The relative risk of gastrointestinal (generally gastric or colorectal) second cancers appears to continue to rise throughout continued long-term follow-up, such a trend has been demonstrated following successful treatment of different primary childhood ${ }^{14}$ and adult ${ }^{15}$ cancers. This is the first case of duodenal carcinoma occurring after a childhood Wilms' tumour. The patient also had a benign duodenal tumour.

Fistulas between the duodenum and colon are uncommon. Previously they have been reported most commonly due to colonic malignancies or Crohn's disease. Even then the overall incidence of duodeno-colic fistula in cases of carcinomas arising around the hepatic flexure is low, although approximately $20 \%$ of such carcinomas are adherent to the duodenum only about one in 600-700 actually fistulates through to the duodenal lumen. ${ }^{16,17}$ Similarly less than 100 cases of duodeno-colic fistula secondary to Crohn's disease have been reported. ${ }^{18}$ Duodeno-colic fistulas have also been reported secondary to penetrating duodenal ulcer, ${ }^{19}$ gallstones and chronic cholecystitis ${ }^{20}$ rupture of pancreatic pseudocysts, ${ }^{21}$ tuberculosis, ${ }^{22}$ infective and inflammatory colitis, ${ }^{22}$ as a sequelae of gastro-duodenal surgery ${ }^{23}$ and even three cases which seemed to arise spontaneously. ${ }^{24}$ There is also a single report of a duodeno-colic fistula due to an intervening metastasis from an oesophageal squamous carcinoma. ${ }^{25}$ We have been unable to find any previous report of a duodeno-colic fistula secondary to a definite primary duodenal carcinoma. Robinson did report one duodenal-colic fistula thought to be secondary to a duodenal ulcer with possible malignant change, however, it is difficult to be certain of the exact sequence in this case. $^{26}$

This case illustrates several interesting and unusual features of duodenal carcinoma particularly the duodeno-colic fistula and the occurrence after a childhood Wilms' tumour. Although the number of gastrointestinal second malignancies following Wilms' tumour remains small, the possibility of such cancers should be considered in the increasing numbers of patients with prolonged survival after childhood Wilms' tumour, especially those treated with radiotherapy. Given the generally poor prognosis of duodenal cancers, prompt investigations into suspicious symptoms is warranted and consideration given to duodenal cancer as a cause of duodenal-colic fistulas.

\section{References}

1. Breslow, N.E., Norkool, P.A., Oldshan, A., Evans, A. \& D'Angia, G.J. Second malignant neoplasms in survivors of Wilms' tumour. J Natl Cancer Inst 1988, 80: 592-595.

2. Blatt, J., Olsan, A., Gula, M., Dickman, P. \& Zaranek, B. Second malignancies in very long term survivors of childhood cancer. Am J Med 1992, 93: 57-60.

3. Kovalic, J.J., Thomas, P.R.M., Beckwith, J.B., Feusner, J.H. \& Norkool, P.A. Hepatocellular carcinoma as second malignant neoplasms in successfully treated Wilms' tumour patients. Cancer 1991, 67: 342-344.

4. Sabio, H., Teja, K., Elkon, D. \& Shaw, A. Adenocarcinoma of the colon after Wilms' tumour. J Paediatr 1979, 95: 424-426.

5. Opitz, J.M. Adenocarcinoma of the colon following Wilms' tumour. J Paediatr 1979, 96: 775.

6. Li, F.P. Colon cancer after Wilms' tumour. J Paediatr 1980 , 96: 954-955

7. Holmes, G., Dunn, G., Cockel, R. \& Brookes, V. Adenocarcinoma of upper small bowel complicating coeliac disease. Gut 1980, 21: 1010-1016.

8. Fell, J. \& Snooks, S. Small bowel adenocarcinoma complicating Crohn's disease. J $R$ Soc Med 1987, 80: 51-52.

9. Haggit, R. \& Reid, B. Hereditary gastrointestinal polyposis syndromes. Am J Surg Path 1986, 10: 871-887.

10. Calmes, J., Rutz, H., Suardek, L. \& Givel, J. Hereditary colorectal cancer observations of a family study. Helv Chir Acta 1992. 59: 349-354.

11. Devilee, P., Van den Broek, M., Slater, R. \& Cornelisse, C. Differences in patterns of allelic loss between two common types of adult cancer, breast and colon carcinoma and Wilms' tumour. Int J Cancer 1991, 47: 817-821.

12. Haber, D.A. \& Housman, D.E. Role of the WT1 gene in Wilms' tumour. Cancer Surv 1992, 12: 105-117.

13. Fisher, J.H., Scoggin, C.H. \& Rogler, C.E. Sequences which flank at $11 \mathrm{p}$ deletion observed in an hepatocellular carcinoma map to 11 p13. Hum Genet 1987, 75: 66-69.

14. Olsen, J.H., Garwicz, S., Hertz, H. et al. Second malignant neoplasms after cancer in childhood or adolescence. $\mathrm{Br} \mathrm{Med} \mathrm{J}$ 1993, 307: 1030-1036. 
15. Swerdlow, A.J., Douglas, A.J., Vaughan Hodson, G. et al. Risk of second cancers after Hodgkins disease by type of treatment. Analysis of 2,846 patients in the British national lymphoma investigation. $\mathrm{Br}$ Med J 304: 1137-1443.

16. Vieta, J.O., Blanco, R. \& Valentini, G.R. Malignant duodeno-colic fistula: report of two cases. Dis Colon Rectum 1976, 19: 542-552.

17. Hakami, M., Dadgostar, D. \& Feshareki, R. Invasive carcinoma of the colon and duodenum with duodeno-colic fistula: report of a case. Am J Proctol 1976, 27: 35-36.

18. Pinchney, L.S., Fantry, G.T. \& Graham, S.M. Gastrocolic and duodeno-colic fistulas in Crohn's disease. J Clin Gastroenterol 1992, 15: 205-211.

19. Ionescu, A., Moisa, V., Sciuca, S. \& Hamburda, M. Supra vaterian duodenal ulcer perforated into the transverse colon. Rev Chir Oncol Radiol O R Oftamol Stomatol Chir 1976, 25: 285-289.
20. Edmonds, P.K. \& Havard, C. Duodeno-colic fistula due to gall stones. Br J Surg 1961, 49: 253-255.

21. Shatney, C. \& Sosin, H. Spontaneous perforation of a pancreatic pseudocyst into the colon and duodenum. Am J C Surg 1973, 126: 433-438.

22. Hammar, B. Benign duodenocolic fistula. Br J Surg 1965, 52: 153-155.

23. Godlevski, A.L. Complex prevention of suture incompetence of the duodenal stump in penetrating duodenal ulcer. Vestn Khir 1989, 142: 32-34.

24. Torrance, B. \& Jones, C. Three cases of spontaneous duodeno-colic fistula. Gut 1972, 13: 627-630.

25. Reissman, P., Steinhagen, R.M. \& Enright, P.F. Duodenocolic fistula; an unusual presentation of eosophageal squamous cell carcinoma. Mt Sinai J Med 1992, 59: 75-78.

26. Robinson, W.W. Duodenal-colic fistula. Sth Med J 1960, 53: 596. 